\title{
O mensageiro, o Alcorão e o sagrado: Alguns apontamentos a partir da Ciência da Religião
}

\author{
The messenger, the Koran and the sacred: \\ Some notes from the Science of Religion
}

Marcelo Lopes*

\begin{abstract}
Resumo
O Islã é uma das religiões que mais cresce no tempo presente. Não obstante, sobretudo no Ocidente, ainda há certo preconceito em relação a essa religião, talvez pelo desconhecimento de suas verdadeiras crenças e práticas. Em vista disso, o presente texto pretende refletir um pouco sobre a religião islâmica. Para tanto, arbitramos três tópicos significativos para proceder à reflexão: o seu mensageiro, o seu livro sagrado e o seu sagrado propriamente dito. Através da lente da Ciência da Religião, focamos, em primeiro lugar, a experiência religiosa do seu profeta fundador - Muhammad. Em seguida, trazemos alguns apontamentos sobre seu livro sagrado - o Alcorão, e, por fim, abordamos alguns aspectos de seu sagrado, mormente em relação à sua divindade - Allah e aos seres espirituais nos quais creem os muçulmanos. Assim, o escopo deste trabalho é iluminar alguns aspectos dessa religião ainda pouco perscrutada no Brasil, e, por fim, levantarmos algumas questões que, pensamos, são pertinentes ao objeto ora em tela.
\end{abstract}

Palavras-chave: islamismo; Muhammad; Alcorão; sagrado; profano.

\begin{abstract}
Islam is one of the fastest growing religions today. Nevertheless, especially in the West, there is still some prejudice against this religion, perhaps because of the ignorance of the people regarding their true beliefs and practices. On the face of it, this article intends to reflect on the Islamic religion. To this end, we chose three significant topics to proceed with this reflection: the central message of Islam, its holy book and its "Sacred". Through the lens of the Science of Religion, we focus, first, the religious experience of its founding prophet - Muhammad. Then we did some notes about its holy book - the Koran, and finally, we discuss some aspects of its sacred, especially concerning its deity - Allah and spiritual beings in which Muslims believe. Thus, the scope of this paper is to illuminate some aspects of that religion still poorly scrutinized in Brazil, and finally, we raise some issues that we think are relevant to the subject at hand.
\end{abstract}

Keywords: Islam; Muhammad; Koran; sacred; profane.

Paper-Comunicação submetida em 31 de julho de 2014 e aprovada em 25 de abril de 2015.

* Doutorando em Ciência da Religião (Religião, Sociedade e Cultura) pelo Programa de Pós-graduação em Ciência da Religião da Universidade Federal de Juiz de Fora. País de origem: Brasil. E mail: montanhista-ms@hotmail.com. 


\section{Considerações Iniciais}

Os monoteísmos semíticos são notadamente religiões de revelação. Afirmar isso implica admitir, conquanto subjacentemente, que, na perspectiva dos fiéis, o sagrado se manifesta ou se auto-revela aos seres humanos no decorrer da história de diversas maneiras distintas. Via de regra, essas auto-revelações dão ensejo à fundação de novas religiões ou a reformas proféticas ${ }^{1}$ no seio de uma determinada religião.

Tais manifestações do sagrado ou auto-revelações na história humana, isto é, no mundo profano, foram denominadas por Mircea Eliade como hierofanias. Segundo este autor,

quando o sagrado se manifesta por uma hierofania qualquer, não só há rotura na homogeneidade do espaço, como também revelação de uma realidade absoluta, que se opõe à não-realidade da imensa extensão envolvente. A manifestação do sagrado funda ontologicamente o mundo (ELIADE, 2008, p. 26, grifo do autor).

Antes de mais nada, no entanto, há que se aclarar um pouco mais o conceito de hierofania. Grosso modo, hierofania é a manifestação do mundo supra-sensível, do sagrado, do extraordinário no cotidiano, isto é, no mundo profano. Quer seja ela uma experiência religiosa singela, quer seja uma experiência religiosa arrebatadora, o que realmente caracteriza uma hierofania é a manifestação do sagrado em si.

$\mathrm{Na}$ tradição judaica, por exemplo, uma simples brisa, como narra a literatura veterotestamentária, significou uma hierofania marcante ocorrida com o profeta Elias no monte Horebe (BÍBLIA TEB, 1 Rs 19. 11-13). Um exemplo emblemático e severo na tradição cristã pode ser encontrado na narrativa 
neotestamentária registrada no livro dos Atos dos Apóstolos, no capítulo 5, por ocasião da morte de Ananias, e que causou forte impacto naquela comunidade religiosa, de modo que "um grande temor se apoderou então de toda a igreja e de todos os que souberam do acontecido" (BÍBLIA TEB, Atos 5.11).

Enquanto o primeiro exemplo de hierofania, isto é, a manifestação do sagrado, do numinoso, parece exprimir “o aspecto - Fascinans do nume” (OTTO, 2007, p. 68), que é, como disse Otto, “- desconcertante, é cativante, arrebatador, encantador, muitas vezes levando ao delírio e ao inebriamento - o elemento dionisíaco entre os efeitos do nume" (2007, p. 68); o segundo exemplo de hierofania enseja aquele sentimento aterrorizante da criatura perante a manifestação do Mysterium Tremendum aventado também por esse autor, que o sagrado inflinge como sendo um sentimento de assombro, de terror mesmo, decorrente do sentimento de criatura perante o Totalmente Outro que se manifesta.

É justamente nesses sentidos que se pode pensar tais fenômenos como exemplos de hierofania, pois tocam ontologicamente o homo religiosus ${ }^{2}$. É assim que hierofania

entendida esta como a irrupção do sagrado, cada uma ao seu modo, permite uma dada e diferente aproximação do sagrado. A hierofania, com poucas exceções, é um epifenômeno que se apresenta a um indivíduo e constitui nele uma experiência fundante ou transformadora, ou mesmo mantenedora de uma forma de religião (MENDONÇA, 2004, p. 35).

Citamos logo acima a título ilustrativo dois exemplos de hierofanias, primeiro do judaísmo e depois do cristianismo. Mas e no Islã 3 , também houve (há) hierofanias? Evidentemente que sim! Mas quais? Responder a tais questionamentos, portanto, será o nosso objetivo principal doravante neste trabalho. Ou seja, evidenciar o que de propriamente religioso houve (há) na

\footnotetext{
${ }^{2}$ Para um aprofundamento sobre o termo ver: Batista Mondin (1980, p.330.).

${ }^{3}$ É importante observar que a palavra Islã tem sua raiz árabe em S-L-M e primeiramente significa paz. Um segundo significado é submissão, em sua transliteração para a língua árabe como "Islam".
} 
experiência de seu derradeiro mensageiro, no Islã como religião do Livro, e na sua relação com o Sagrado, é o que pretende este ensaio.

\section{E no princípio o sagrado encontrou Muhammad}

Muito embora a teologia islâmica baseada na exegese corânica ortodoxa, tenha atribuído ao Islã uma atemporalidade mítica, a gênese cronológica dessa religião, do ponto de vista histórico, pode ser precisamente situada no espaço e no tempo, qual seja, a península arábica do século VII da era comum.

Sem muito esforço, percebe-se que a construção mítica de sua gênese intenta remeter-se ao período patriarcal bíblico: “Da religião, Ele legislou, para vós, o que recomendara a Noé, e o que recomendáramos a Abraão e a Moisés e a Jesus: 'Observai a religião" (ALCORÃO, 42:13)4, cujo complemento lógico é: "Por certo, a religião, perante Allah, é o Islão" (ALCORÃO, 3:19). Não obstante o islamismo reconhecer muitos outros profetas5, segundo crêem, o derradeiro mensageiro 6 de Allah foi Muhammad.

A situação religiosa da península arábica pré-islâmica pode ser descrita como majoritariamente politeísta. Essa religiosidade politeísta foi denominada posteriormente como "jahiliyyah - período de ignorância e cegueira antes da revelação” (DEMANT, 2008, p. 24, grifo do autor). Muhammad foi vocacionado como mensageiro aos quarenta anos de idade em meio a essa jahiliyyah.

\footnotetext{
${ }^{4}$ Para os muçulmanos o Alcorão somente pode ser considerado como tal se estiver em seu vernáculo original, isto é, o árabe. Caso esteja em qualquer outro idioma, ele é considerado uma tradução, mas não o Alcorão propriamente dito. Assim, muito embora as referências citadas neste trabalho sejam extraídas da obra: NARS, Helmi. TRADUÇÃo do sentido do Nobre Alcorão para a língua portuguesa. Medina: Complexo de impressão do Rei Fahd, [entre 1982 e 1992]. 1065 p, referenciaremos nossas citações como sendo do próprio Alcorão, fazendo, todavia, esta ressalva inicial.

5 Segundo o teólogo islâmico Sami Armed Isbelle, o número total de profetas de todas as épocas é de "124.000, e o Alcorão nos relata que Deus nos informou os nomes de alguns deles apenas" (2003, p. 139).

6 Cumpre aqui destacar que no Islã há uma diferença entre profeta e mensageiro. Grosso modo, o profeta é um homem escolhido por Allah para ratificar uma mensagem já dada outrora, ou seja, não há originalidade. Enquanto que o mensageiro traz, necessariamente, uma nova revelação. Decorre dessa compreensão que todo mensageiro é um profeta, mas os profetas não são mensageiros.
} 
É preciso nos determos um pouco nessa vocação, pois ela se acha impregnada de hierofanias. A historiadora das religiões Karen Armstrong descreveu o primeiro contato de Muhammad com o sagrado da seguinte forma:

\begin{abstract}
uma revelação divina realizou-se no monte Hira em 610, na sétima noite do Ramadã, quando Maomé foi arrancado do sono e se sentiu tomado por uma devastadora presença divina. Mais tarde, ele descreveu essa inefável experiência em termos tipicamente árabes. Contou que um anjo lhe apareceu e lhe ordenou, com um tom seco: "Recita!" (iqra!). Como os profetas hebreus que muitas vezes relutavam em expressar a Palavra de Deus, Maomé recusou-se: "Não sou recitador!", protestou. Não era kahim, adivinho extático que dizia recitar oráculos inspirados. Mas o anjo simplesmente o envolveu num abraço tão apertado que lhe deu a sensação de expulsar todo o ar de seu corpo. Quando achava que não ia mais agüentar, o anjo o soltou e repetiu: "Recita!" (iqra!). Mais uma vez, ele se recusou e mais uma vez o anjo o abraçou até fazê-lo sentir que chegara aos limites da resistência. Por fim, depois de um terceiro abraço aterrorizante, as primeiras palavras de uma nova Escritura jorraram da boca de Maomé (ARMSTRONG, 2008, p. 182-183).
\end{abstract}

Baseado no relato dessa experiência religiosa, até mesmo o leitor mais despreocupado percebe, com bastante facilidade, nessa hierofania, o aspecto tremendum do nume com o qual Muhammad teve contato. Essa experiência religiosa foi tão marcadamente emblemática que o próprio nome da religião nascitura refletiu, de um modo ou de outro, o resultado dessa hierofania, uma vez que "a palavra islam (islã, em português) significa exatamente submissão" (DEMANT, 2008, p. 25, grifo do autor).

Após ter a primeira experiência com o sagrado, Muhammad não mais cessou de tê-las. Na verdade, "as revelações teriam continuado durante sua vida inteira" (DEMANT, 2008, p. 26). Contudo, aquela primeira experiência foi de tal modo abissal, em termos ontológicos, que "naquele momento, correndo para fora da gruta, decidiu jogar-se do cume para a morte" (ARMSTRONG, 2008, p. 183), talvez numa tentativa desesperada, presume-se, de fugir do sagrado que o solapava. 
"Na encosta da montanha, porém, teve outra visão de um ser que, mais tarde, identificou como o anjo Gabriel" (ARMSTRONG, 2008, p. 183), e este lhe revelou que sua missão era revelar a derradeira e verdadeira religião à humanidade: o Islã. A revelação, no entanto, não foi instantânea, ao contrário, foi paulatina. Muhammad ficou tão assombrado com aquela hierofania que, ao chegar a sua casa, "arrastando-se pelo chão, tremendo com violência, jogou-se no colo da esposa. 'Cobre-me! Cobre-me!', gritou, pedindo-lhe que o protegesse da presença divina” (ARMSTRONG, 2008, p. 184).

As hierofanias foram uma constante em toda a vida do mensageiro após ter sido sobrenaturalmente vocacionado por Allah, por intermédio do anjo Gabriel. Uma das hierofanias mais conhecidas é a chamada "Viagem Noturna" na qual, segundo o mito, Muhammad foi levado miraculosamente de Meca a Jerusalém e depois ascendeu às esferas celestes. O Alcorão registra essa hierofania:

Glorificado seja Quem fez Seu servo Muhammad viajar à noite - da Mesquita Sagrada para a Mesquita Al-Aqsā, cujos arredores abençoamos - para mostrar-lhe, em seguida, alguns de nossos sinais. Por certo, Ele é O Oniouvinte, O Onividente (ALCORÃO, 17:1).

Em todo caso, porém, a quase totalidade das hierofanias tinham um propósito maior que ia além da experiência extática, qual seja, a revelação do sagrado Alcorão como a derradeira revelação de Allah à humanidade através de seu último mensageiro.

\section{Um livro sagrado advém de um analfabeto}

Segundo Armstrong (2008), e como se pode inferir com base nos relatos hierofânicos das revelações, a recepção da revelação corânica, foi um processo doloroso e, como todo processo criativo, esse também foi demasiadamente difícil: “nunca recebi uma revelação sem sentir que minha alma me estava sendo arrancada', disse Maomé anos depois” (ARMSTRONG, 2008, p. 185). 
Não raro, o mensageiro de Allah

entrava em transe e em algumas ocasiões parecia perder a consciência; suava em profusão, mesmo num dia frio, e muitas vezes sentia um peso interior, como um sofrimento, que o obrigava a baixar a cabeça entre os joelhos, uma posição, uma posição adotada por alguns místicos judeus contemporâneos quando entravam num estado alternativo de consciência - embora Maomé não soubesse disso (ARMSTRONG, 2008, p. 185).

Foram nesses momentos extáticos que o Alcorão foi revelado, digo, recitado. Recitado em primeiro lugar porque "a palavra Alcorão na língua árabe significa leitura por excelência ou recitação" (ISBELLE, 2003, p. 106), em segundo lugar porque essa foi a ordem do anjo Gabriel no monte Hira, e em terceiro lugar porque "Maomé, que não sabia ler nem escrever, recitava-o em voz alta, os muçulmanos o decoravam e os poucos alfabetizados anotavam-no. Cerca de vinte anos após a morte de Maomé, fez-se a primeira compilação oficial da revelação" (ARMSTRONG, 2008, p. 186).

O Alcorão tem importância fulcral para os muçulmanos porque

o centro da civilização islâmica é um livro, $O$ Livro, segundo os muçulmanos: o Corão. De acordo com a tradição, ele foi revelado a Mohamed por intermediação do arcanjo Gabriel. Na tradição cristã, de outra parte, o centro não é o Evangelho, mas sim o Cristo, o Logos, o Verbo divino feito carne. Os muçulmanos consideram o Corão o "Verbo feito Livro". O Profeta é o meio através do qual a revelação divina - o Corão - foi transmitida aos homens. No Cristianismo, a revelação é o próprio Cristo, "verdadeiro homem e verdadeiro Deus". E, assim como no Cristianismo o Verbo foi gerado por uma "Virgem", do mesmo modo no Islã o Livro foi escrito por um "iletrado", Mohamed, o que simbolicamente é bastante significativo (AZEVEDO, 2000, p. 38).

Muito embora Muhammad não tenha escrito o Alcorão e sim seus discípulos, de fato, é bastante significativa a comparação que Azevedo procedeu com a tradição cristã. Mas não é somente nesse aspecto que o Livro do Islã tem seu caráter sagrado. Na verdade, o Alcorão sacraliza o cosmos na medida em que concebe a pertinência e a influência da religião islâmica em todos os âmbitos da vida humana, desde a liturgia cúltica à política estatal. 
É, sem dúvida alguma, uma concepção sacral e sacralizante do Alcorão que legitima essa cosmovisão islâmica. Basta lembrarmos que

o cristianismo ensina que "o Verbo se fez carne, e habitou entre nós" (Jo 1.14). Jesus é a revelação. No islamismo, Maomé é apenas um intermediário, pois a verdadeira revelação ocorre no próprio Corão. No cristianismo a Palavra de Deus se tornou uma pessoa; no islamismo, um livro. Outra diferença importante entre a Bíblia e o Corão é que a Bíblia é um texto sagrado histórico, ao passo que para os islâmicos, o Corão é "incriado" e existe para sempre (DAMIÃO, 2007, p. 313, grifo nosso).

Tal concepção da literatura sagrada gera uma mundivisão totalizante da vida, na qual a ingerência do Alcorão não fica restrita à esfera religiosa, mas vai além, legislando sobre todos os aspectos da existência do muçulmano. Ora, uma vez que se crê que o Alcorão é a única verdade revelada e seu mensageiro é o derradeiro dos mensageiros, de fato, é compreensível que se espere deste livro uma completude religiosa que seja suficientemente abarcante, tanto na esfera particular como na esfera pública. E esta é justamente a concepção que o muçulmano tem do Alcorão.

O teólogo islâmico Sami Armed Isbelle vai além e assevera o caráter universal da mensagem corânica:

Com a mensagem final, através do último mensageiro, ela passou a ser direcionada para toda a humanidade e válida para todos os tempos até o dia do juízo final. Essa religião aborda tudo que é importante na vida do ser humano por meio dos ensinamentos contidos nas suas fontes principais, que são o Alcorão, último livro revelado por Deus para toda a humanidade, e a Sunna, ou seja, os ditos e as práticas do profeta Muhammad (Que abênção e a paz de Deus estajam sobre ele 7 ). No Islam, não existe uma separação da vida de devoção e da vida diária do homem. O Islam é um sistema de vida completo que possui seus próprios sistemas político, econômico, jurídico e penal, que são, na verdade, os temas desse livro. Desse modo, procuraremos mostrar como se organiza o Estado Islâmico através desses

\footnotetext{
${ }^{7}$ Há uma tradição no Islã que sempre que o nome do profeta Maomé (Muhammad) é mencionado, deve-ser fazer a seguinte saudação: "Que abênção e a paz de Deus estajam sobre ele". Essa saudação é também abreviada como S.A.A.S ou S.A.W.S, que expressa essa mesma saudação em árabe: șallā llāhu 'alay-hi wa-sallam ou Sallallahu alayhi Wa sallam.
} 
sistemas, já que a religião como um todo só poderá ser posta em prática com a existência de um Estado Islâmico (ISBELLE, 2007, p.1, grifo nosso).

Essa cosmovisão descrita acima é uma concepção teológica e, como era de se esperar, nela há um tom apologético na qual se interpenetram religião e política, religião e Estado, religião e judiciário, explicitando dessa forma o desejo de ingerência da religião em todos os âmbitos da vida.

No entanto, tal condicionamento ou intento, foi notado também pelas demais Ciências Humanas. Podemos citar, como um bom exemplo dessa leitura mais científica do fenômeno, a análise feita pelo historiador da terceira geração dos Annales ${ }^{8}$ Marc Ferro:

De fato, durante séculos - da destruição do Templo de Jerusalém até a criação do Estado de Israel -, o judaísmo foi realmente uma religião, e uma religião no sentido ocidental e atual da palavra. Enquanto desde a conversão de Constantino, em 312 d.C., o cristianismo foi associado ao Estado antes de se fundir a ele, tanto que as modalidades da relação entre Igreja e o Estado alimentaram toda a história do Ocidente. O Islã, ao contrário, desde a origem é de uma só vez o Estado, o poder político e o comunitário, fazendo um conjunto com a religião. Esta não é apenas um simples setor da vida, ainda que, segundo as circunstâncias, seus adeptos passem de uma religiosidade inerte, com seus conformismos, a uma fé profunda ou o contrário. De forma que distinções tais como a distinção entre a Igreja e o Estado e aquela que se formula entre a vida privada e a ordem pública não têm o mesmo sentido que no mundo cristão. A dissociação que pode existir no Ocidente entre essas instâncias não implica, em qualquer parte e a qualquer hora, uma solução ideológica do político e do religioso. O Islã é, de qualquer forma, uma "cultura histórica à qual se agrega o Estado" (A. Laroui). De fato, a ortodoxia distingue de um lado, desde os séculos IX e X, os Estado islâmico teocrático das origens, caso histórico "miraculoso", e, de outro lado, os Estados muçulmanos ulteriores, não - teocráticos e nunca clericais, que separam o político do religioso (FERRO, 2008, p. 16).

\footnotetext{
${ }^{8}$ Para uma melhor compreensão do termo, ver, por exemplo, o artigo de José Costa D’ Assunção Barros (v. 4 n. 8, jul/dez 2010).
} 
Com essa concepção totalizante de mundo ${ }^{9}$, o Islã precisa de uma base sólida que possa nortear precisamente todo o modo de agir nesse mundo sagradoprofano. O Alcorão é, por excelência, essa base e esse norte. Fala não somente do celeste porvir, mas do cotidiano, sobretudo. O Islã, nesse sentido, talvez, mais que os outros monoteísmos semíticos, leva ao limite o ser uma religião do Livro.

Não obstante, o Alcorão, embora considerado o centro da religiosidade islâmica, foi revelado por uma realidade superior a qual se atribui sua autoria e legitimidade e autoridade. Assim, muito embora o Alcorão tenha abissal importância, ele não se constitui um fim em si mesmo. Antes, seu intuito principal é prescrever a reta doutrina de modo que os submissos vivam de acordo com a vontade de Allah, para que sejam aprovados no dia do juízo final. Portanto, o Alcorão veio de Allah e aponta para Allah. Mas, afinal, quem é Allah?

\section{0 sagrado no Islã: uma brevíssima sinopse.}

Talvez seja interessante aqui rememorar a útil contribuição de Eliade quando afirma "que o sagrado e o profano constituem duas modalidades de ser no mundo, duas situações assumidas pelo homem ao longo da sua história" (2008, p. 20, grifo do autor). No Islã essa concepção se aprofunda e se complexifica como veremos a seguir.

Allah é o nome da divindade no Islã. Até aqui não há novidade. Cumpre sublinhar, no entanto, que Allah é o termo que em árabe designa Deus apenas, e não uma divindade específica, tanto que os cristãos árabes utilizam tal termo para o Deus da tradição cristã. Mas mesmo sendo um termo genérico, também o é bastante significativo e peculiar, pois a palavra árabe Allah

9 Para um aprofundamento dessa temática, recomendamos ao leitor o livro 0 Estado Islâmico e sua organização: sistema político, sistema econômico, sistema jurídico, sistema penal, conceito de jihad, do teólogo islâmico Sami Armed Isbelle. 
não admite gênero, nem número e nem grau, caracterizando dessa forma um Deus Único, enquanto que em outras línguas a palavra Deus pode ter gênero como, por exemplo, na língua portuguesa temos deusa, e número, como deuses. Em função dessa particularidade é que alguns muçulmanos preferem utilizar o termo em árabe ao se referir a Deus (ISBELLE, 2003, p. 11).

À semelhança do cristianismo e do judaísmo, o islamismo reteve a concepção de um cosmos repleto de seres espirituais que, de uma forma ou de outra, influenciam os seres humanos. Todavia, antes de pormenorizar esses seres espirituais, é necessário ainda tratar um pouco mais sobre Allah.

A concepção islâmica sobre a divindade pode ser entendida como um monoteísmo estrito, cujo fio condutor é a crença na unicidade do criador. Esta,

é a crença convicta do muçulmano de que Deus é o único Criador, o Único Sustentador, o Único Organizador de todo universo, Quem dá a vida e a morte, o Soberano e Regente. [...] Contudo, somente a crença na unicidade do Criador não é suficiente para fazer de alguém muçulmano, porque, no tempo do profeta Muhammad (S.A.A.S), os incrédulos confessavam esse tipo de unicidade. Mas nem por isso, ele os considerou muçulmanos, mas os combateu e os classificou como politeístas, pois apesar de acreditarem num Único Criador, adoravam ídolos junto a Deus (ISBELLE, 2003, p. 17).

Aqui fica bastante clara a distinção da concepção de Deus entre o islamismo e o cristianismo, sobretudo. A ressalva que é feita acerca dos incrédulos que confessavam a unicidade de Deus diz respeito aos cristãos como um todo. Dessa forma, Muhammad rejeita a crença na trindade, mas não só, pois nem mesmo a unicidade de certos cristãos fora tolerada. Essa discordância, todavia,

nada tinha de surpreendente, uma vez que os cristãos que o Profeta conhecia, habitantes da Síria e do Egito, eram sobretudo monofisistas ou nestorianos - e, portanto, também rejeitavam os dogmas da trindade. Tais dogmas, proclamados em idioma grego e no império (antigo Império Romano do Oriente), estavam associados a uma cultura e a um poder estranhos ao universo da Arábia (VALLET, 2002, p. 94-95). 
De fato, a noção da unicidade e transcendência divina está tão profundamente entranhada no Islã que o próprio rito de conversão, isto é, a shahada (testemunho ou profissão de fé) impõe o reconhecimento dessa realidade. Sobretudo sua primeira parte que, talvez seja a mais importante, enseja tal entendimento conforme se pode observar logo abaixo:

O testemunho engloba a crença islâmica, quando pronunciamos a primeira parte que é Achhadu Na Lá Iláha illa Allah, ou seja, Testemunho que não há outra divindade (merecedora da nossa adoração) a não ser Deus (ISBELLE, 2003, p. 195, grifo do autor).

\title{
Segundo Hans Küng,
}

\begin{abstract}
a profissão de fé (shahada) é indiscutivelmente e sem qualquer dúvida a mensagem central do Islã. É de uma extrema simplicidade, podendo efetivamente ser reproduzida por apenas duas palavras. A primeira palavra: Alá. Portanto, a fé no Deus único, que não admite nenhuma "associação" com uma deusa, com um filho ou uma filha. A fé em Alá, o Deus único, é o primeiro dever do muçulmano e o fundamento da comunidade islâmica, o conteúdo único de sua oração litúrgica. Ela constitui o elo espiritual da unidade entre todas as tribos e povos islâmicos. A segunda palavra: Maomé. Por conseguinte, a adesão ao último e definitivo Profeta, o "selo" dos profetas (KÜNG, 2004, p. 255).
\end{abstract}

Assim, a divindade do Islã distancia-se da divindade do cristianismo, mas também do judaísmo. Muito embora a unicidade de Deus no judaísmo talvez seja mais próxima do Islã do que a do cristianismo, dificilmente haverá compatibilidade de concepções. Isso ocorre na exata na medida em que no Islã não se consegue compreender certas antropopatias e antropomorfismos descritos no Tanach $^{10}$, tais como: Deus se arrependendo (Shemot [Êxodo] 32.14), bem como um simples mortal como Jacó lutando com Deus e prevalecendo (Beréshit [Gênesis] 32.24-32), por exemplo.

\footnotetext{
${ }^{10}$ Esta palavra, um acrônimo, significa o núcleo dos livros sagrados do Judaísmo: Torá (5 livros), Profestas (8) e Escritos (11), totalizando 24 livros.
} 
Em razão dessas acepções, portanto, parece haver motivos suficientemente sólidos para pensar que, na concepção muçulmana, de fato, Allah não é o mesmo Javé do Tanach, ou o Deus triuno da tradição cristã. Dessa maneira, a concepção de Allah no Islã reforça a ideia do exclusivismo monoteísta levado ao limite.

Já em relação aos seres espirituais, segundo o próprio Alcorão, Allah criou os seres espirituais que povoam os cosmos. Portanto, há também seres sagrados além da própria divindade. Nesse sentido, o islamismo se assemelha tanto ao judaísmo quanto ao cristianismo, uma vez que ambos possuem uma gama bastante ampla de seres espirituais pertencentes à esfera do sagrado.

No Islã, há basicamente dois tipos de seres, quais sejam, os anjos e os gênios. Segundo Isbelle (2003), os anjos foram criados de luz e a maioria deles tem uma aparência bela. Por outro lado, há anjos

que possuem uma forma assustadora, podemos citar os anjos responsáveis pelo inferno e pelo castigo. Eles não têm o livre arbítrio como os seres humanos e os gênios. [...] Eles apenas executam as ordens de Deus. Eles não possuem sexo, não se alimentam (ISBELLE, 2003, p. 65).

Cumpre ainda ressaltar que os seres humanos não podem ver os anjos, salvo se estes estiverem na forma humana. Somente os profetas é que podiam vê-los. Assim como na tradição judaica e cristã, os anjos são hierarquicamente divididos em ordem de importância e função. Contudo, não se sabe ao certo o número total desses seres.

Já com relação aos gênios, percebe-se "a outra face do sagrado”.

A palavra árabe jinn significa aquilo que se esconde, que está oculto, que não é percebido pelos nossos sentidos. Não sabemos muito sobre eles, a não ser o que Deus nos relatou a seu respeito. São criaturas criadas por Deus do fogo (ISBELLE, 2003, p. 70, grifo do autor). 
Os gênios, diferentemente dos anjos, possuem livre arbítrio. Segundo creem os muçulmanos, os gênios vivem entre os seres humanos de uma maneira quase que despercebida, pois se alimentam, bebem e, inclusive, tem uma religião ${ }^{11}$, perfazendo praticamente um mundo paralelo. Possuem ainda a capacidade de se hipostasiar em diversas formas como, por exemplo, as dos animais.

Retomaremos aqui a ideia dos gênios como "a outra face do sagrado". Isso porque, sobre os gênios, pensa-se que

as criaturas mais mentirosas de todas as criaturas são os gênios, demônio é o nome dado a todo gênio descrente que se rebela contra Deus. Lúcifer, que é o pai dos demônios, era um gênio como nos relata o Alcorão: (18:50) - 'E (lembra-te) de quando dissemos aos anjos: Prostrai-vos ante Adão! Prostraram-se todos, menos Lúcifer, que era um dos gênios, e que se rebelou contra a ordem do seu Senhor...' (ISBELLE, 2003, p. 71).

Tal percepção nos remete necessariamente à abordagem de Durkheim (1989) sobre o sagrado puro e o sagrado impuro. Não que isso seja algo inédito nos monoteísmos, mas certamente há especificidades bastante significativas que, por absoluta falta de espaço, não poderemos aprofundar em suas características.

Sobre a ambiguidade do sagrado, Durkheim afirmou que

o puro e o impuro não são, portanto, dois gêneros separados, mas duas variedades do mesmo gênero que compreendem todas as coisas sagradas. Há duas espécies de sagrado, um fasto, e o outro nefasto, e não somente entre as duas formas opostas não existe solução de continuidade, mas ainda, um mesmo objeto pode passar de uma à outra sem mudar de natureza. Com o puro, faz-se o impuro, e vice-versa. É na possibilidade dessas transmutações que consiste a ambigüidade do sagrado (DURKHEIM, 1989, p. 488).

11 Isbelle afirma que, "dentre os gênios há os que são muçulmanos, cristãos, judeus, budistas e os que seguem outras denominações" (2003, p. 70). 
Nesse sentido, no Islã o sagrado não foge à regra, pois percebe-se que também nele,

as força [sic!] religiosas são de duas espécies. Umas são benfazejas, guardiãs da ordem física e moral, dispensadoras da vida, da saúde, de todas as qualidades que os homens prezam: [...] desempenham a mesma função e tocam a consciência dos fiéis da mesma maneira: o respeito que inspiram é mesclado de amor e de reconhecimento. - Por outro lado, existem forças más e impuras, produtoras de desordens, causas de morte, de doenças, instigadoras de sacrilégios. O único sentimento que o homem tem por elas é um temor onde geralmente entra um pouco de horror (DURKHEIM, 1989, p. 485).

Assim, o sagrado no Islã tem pontos de contato bastante semelhantes tanto no judaísmo quanto no cristianismo. Entretanto, suas peculiaridades também o afastam sobremodo desses monoteísmos, de modo que, o que se pode afirmar com maior precisão é que o Islã tem um riquíssimo sagrado a ser explorado por aqueles que se interessam por tal temática. Fica aqui, então, a título de sugestão, este desafio heurístico, pensamos, sobremodo profícuo.

\section{Observações finais}

À modo de conclusão, cumpre relembrar que os primórdios do Islã foram marcadamente hierofânicos, ou seja, o sagrado se manifestando no mundo profano dos homens, sobretudo para conceder a derradeira revelação, isto é, o Alcorão, através do último dos profetas, Muhammad, segundo creem os muçulmanos.

Portanto, longe de ser uma forma de religião exótica, o Islã, na verdade tem sido vítima de preconceitos por vezes infundados, fruto, talvez, de profundo desconhecimento de suas crenças e práticas; além das (des) informações amplamente propaladas pela mídia sensacionalista a respeito de terroristas islâmicos, o que gera o crasso erro de generalizar o particular, o especifico e minoritário. 
De fato, o Islã possui sim algumas particularidades que o difere dos demais monoteísmos, porém não lhes é superior ou inferior por isso, apenas diferente. Portanto, neste texto, buscamos iluminar alguns aspectos dessa grande religião monoteísta a partir de alguns poucos apontamentos feitos através da lente da Ciência da Religião. Obviamente, não arranhamos sequer a superfície do arcabouço de crenças e práticas do Islã, mas pensamos ter contribuído de maneira singela para alargar a compreensão do público que se interessa por essa religião.

Por fim, mas não menos importante, lançamos um desafio, qual seja, entendendo que o Islã não é uma religião fossilizada, mas uma religião viva e pujante, certamente ainda hoje há a possibilidade de encontrar-se com esse sagrado islâmico. Assim, há ainda muito que perscrutar no Islã. Referimo-nos aqui, por exemplo, à tradição sufi, se bem que num sentido inverso, pois se na hierofania é o sagrado se manifesta ao homem, no sufismo é o homem que busca o contato com o sagrado. Mas isso é assunto para outras pesquisas...

\section{REFERÊNCIAS}

ARMSTRONG, Karen. Uma história de Deus: quatro milênios de busca do judaísmo, cristianismo e islamismo. São Paulo: Companhia das Letras, 2008.

AZEVEDO, Mateus Soares de. Iniciação ao Islã e Sufismo. Rio de Janeiro: Nova Era, 2000.

BARROS, José Costa D' Assunção. A escola dos Annales: considerações sobre a História do Movimento. Revista História em Reflexão: v. 4, n. 8 - UFGD - Dourados, jul/dez 2010. Disponível em: $<$ http://www.periodicos.ufgd.edu.br/index.php/historiaemreflexao/article /view/953/588>. Acesso em: 25 mai. 2014.

BÍBLIA - Tradução Ecumênica. Tradução: L.J. Baraúna. et al. São Paulo: Loyola, 1994.

DAMIÃO, Valdemir. História das Religiões: sua influência na formação da humanidade. Rio de Janeiro: CPAD, 2007.

DEMANT, Peter. O mundo muçulmano. São Paulo: Contexto, 2008. 
DURKHEIM, Émile. As formas elementares da vida religiosa: o sistema totêmico na Austrália. São Paulo: Paulinas, 1989.

ELIADE, Mircea. O sagrado e o Profano: a essência das religiões. São Paulo: Martins Fontes, 2008.

FERRO, Marc. O choque do Islã: séculos XVIII-XXI. Rio de Janeiro: Biblioteca do Exército, 2008.

ISBELLE, Sami Armed. Islam: a sua crença e a sua prática. Rio de Janeiro: Qualitymark, 2003.

ISBELLE, Sami Armed. O Estado Islâmico e sua organização: sistema político, sistema econômico, sistema jurídico, sistema penal, conceito de jihad. Rio de Janeiro: Qualitymark, 2007.

KÜNG, Hans. Religiões do mundo: em busca dos pontos comuns. Campinas: Verus, 2004.

MENDONÇA, Antonio Gouvêa. A experiência religiosa e a institucionalização da religião. Estudos Avançados, São Paulo, v. 18, n.52, p. 29-46, set./dez. 2004. Disponível em: <http://dx.doi.org/10.1590/So103-40142004000300004>. Acesso em: 27 ago. 2013.

MONDIN, Batista. O homem. Quem é ele? Elementos de antropologia filosófica. São Paulo: Paulus, 1980.

NARS, Helmi. Tradução do sentido do Nobre Alcorão para a língua portuguesa. Medina: Complexo de impressão do Rei Fahd, [entre 1982 e 1992].

OTTO, Rudolf. O sagrado: os aspectos irracionais na noção do divino e sua relação com o racional. Petrópolis: Vozes, 2007.

VALLET, Odon. Uma outra história das religiões. São Paulo: Globo, 2002. 